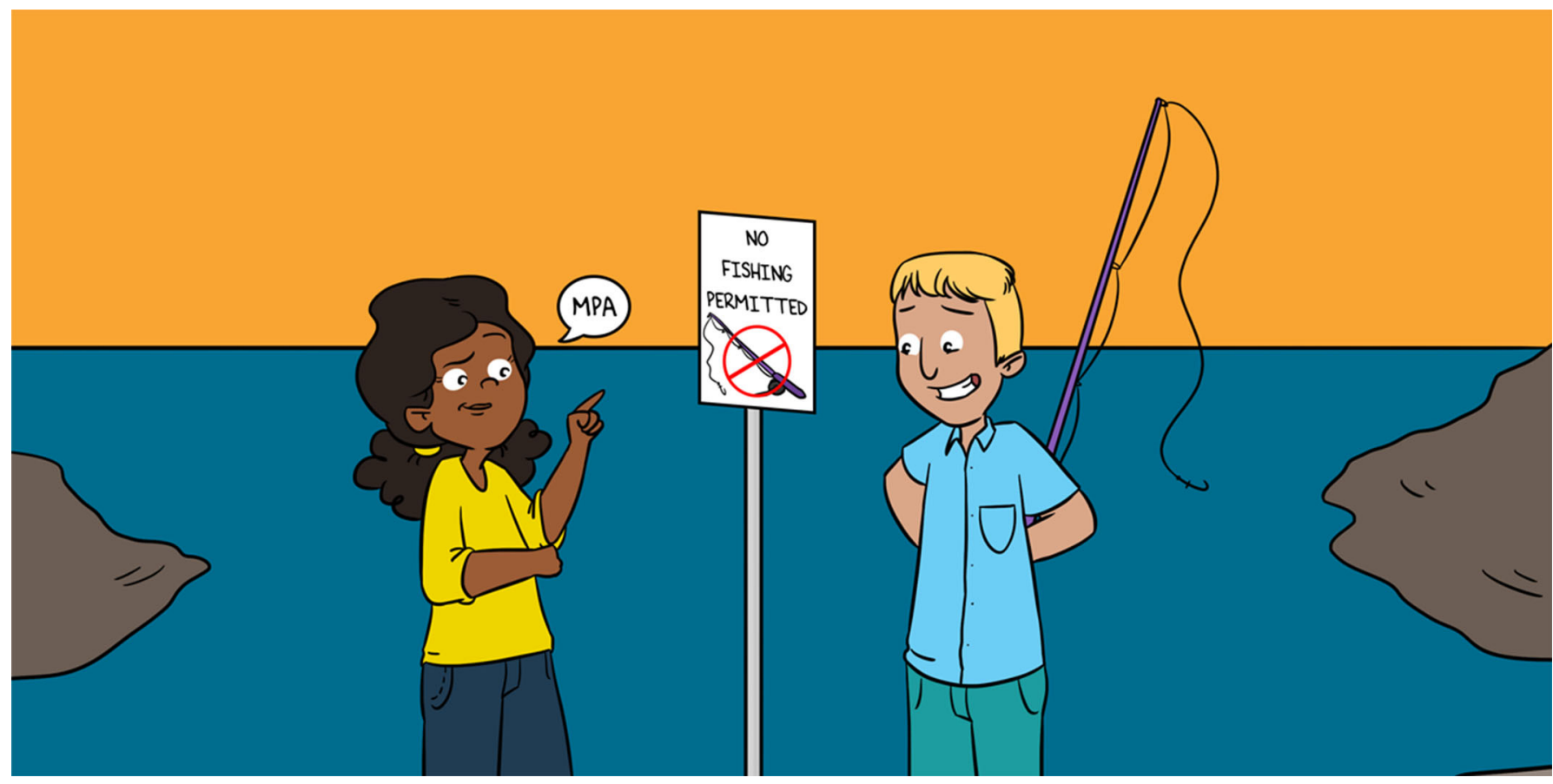

\title{
MARINE PROTECTED AREAS: A WAY TO PROTECT OUR OCEANS
}

\section{Emily S. Nocito * and Cassandra Brooks}

Environmental Studies Program, University of Colorado-Boulder, Boulder, CO, United States

YOUNG REVIEWER:

LUANA

AGE: 15
Have you ever walked around a forest or park, and noticed signs saying things like: "Do not Pick Flowers" or "Do not Feed the Animals"? These signs indicate that the area you are in is being protected from humans. When these protected spaces are in the ocean, they are called marine protected areas. Marine protected areas vary in type, from heavily protected areas, to areas where visitors can use the ocean for recreation. Special rules and regulations protect and conserve underwater habitats, plants, and animals in these areas. Marine protected areas exist all over the world and can result in more and bigger fish, which can lead to a healthier ocean. While it is not easy to create such an area, local community groups, single countries, and even big groups of countries have worked to create marine protected areas, ensuring that their oceans are protected and healthy. 


\section{WHAT ARE MARINE PROTECTED AREAS?}

Have you ever gone to a forest that has special rules in place, like maybe a rule that you cannot pick flowers? These rules are meant to protect the plants and animals in the forest. Just like on land, special rules can exist for parts of the ocean, too. They are called marine protected areas (MPAs), and they are areas that may protect habitats, species, or ecosystems [1]. MPAs might also protect areas that have special significance to a culture or a religion [1]. Just like parks on land, an MPA needs to be managed with rules, such as whether fishing is allowed, or how many fish can be caught. There are not any rules about size-an MPA can be small or really big; some are larger than a football field [1, 2]!

\section{TYPES OF MARINE PROTECTED AREAS}

There is not just one type of MPA. Rather, there is a long list of types that allow communities to choose what MPA type fits best with their needs. The International Union for Conservation of Nature (IUCN) lists six types of MPAs. Each MPA has a different description and goal (Table 1). For example, MPAs classed as category $1 \mathrm{~A}$ are strictly protected to preserve biodiversity while limiting how humans use the space; they are often called "no take zones," because only researchers are allowed inside them, and only if they have gotten permission from the managers of the MPA. The 11 marine reserves within the USA's Channel Islands National Marine Sanctuary fall within this category (Figure 1). Similarly, category 3 MPAs allow for the protection of the amazing natural wonders that the ocean houses. For example, the Blue Hole Natural Monument in Belize features a circular, deep underwater sinkhole (Figure 1). This is a rare feature and its surrounding ecosystem is protected as a category 3 MPA [1].

Almost all categories focus on the marine area as a whole, from habitats, to plants, to species. This changes with a category 4 MPA. The goal of a category 4 MPA is to protect something specific, such as a species of seabird, or sea turtles, or mangrove forests. The South Ari Atoll MPA in the Maldives, e.g., was created to protect and conserve whale sharks that are native to their waters (Figure 1) [1]. Researchers recognize that humans have long relied on the ocean for food or for sport. Category 5 MPAs look to protect the ocean that has value to a community. For example, Apo Island in the Philippines allows for tourism that does not harm the environment and for locals to use the ocean through traditional management (Figure 1) [1]. Lastly, there is category 6 . This type of MPA allows both conservation and sustainable use. This means that, in addition to protecting species and habitats, humans can use the ocean (they can fish or sail), if it is done in way that does not harm biodiversity. catch so many fish that there are not enough fish for

future generations. 


\section{Table 1}

International Union for Conservation of Nature (IUCN) descriptions of categories of marine protected areas and their goals. Adapted from Day et al. [1].

\begin{tabular}{ll}
$\begin{array}{l}\text { Category } \\
\text { number }\end{array}$ & Description \\
\hline $1 \mathrm{~A}$ & $\begin{array}{l}\text { Strictly protected areas that look to } \\
\text { preserve biodiversity and geologic } \\
\text { features. Human impact, such as } \\
\text { through visiting or fishing, is strictly } \\
\text { controlled and limited. }\end{array}$
\end{tabular}

1B

An area that is protected and managed to conserve biodiversity. The area may have been slightly modified by humans but does not have humans living within the area.

2

Areas that protect the ecosystem while allowing humans to use the land, such as through recreation or education.

Areas that protect a specific natural feature.

4

Areas that protect a specific species or habitat.

Areas with a long history of humans using the natural space.

To protect ecosystems and their resources, while encouraging sustainable use.

\section{Main goal}

To conserve ecosystems, species, and/or geological features.

To protect areas that are undisturbed by significant human activity, so that future generations can experience the area in its natural form.

To protect biodiversity while promoting education and recreation.

To protect natural features and their surrounding biodiversity and ecosystems.

To protect, conserve, and restore species and habitats.

To protect and sustain the marine environment, and to allow humans to use and manage the space through traditional practices.

To balance conservation and sustainable use of the area.
Figure 1

Map of Global MPAs.

The dark blue represents where MPAs are present on our Earth. MPAs mentioned in this article are highlighted by the compass icons in the legend. Due to the map projection, the Ross

Sea is labeled twice, but imagine this map wrapped around a globe and you will notice that the Ross Sea is connected into one large MPA (Data from protectedplanet.net)

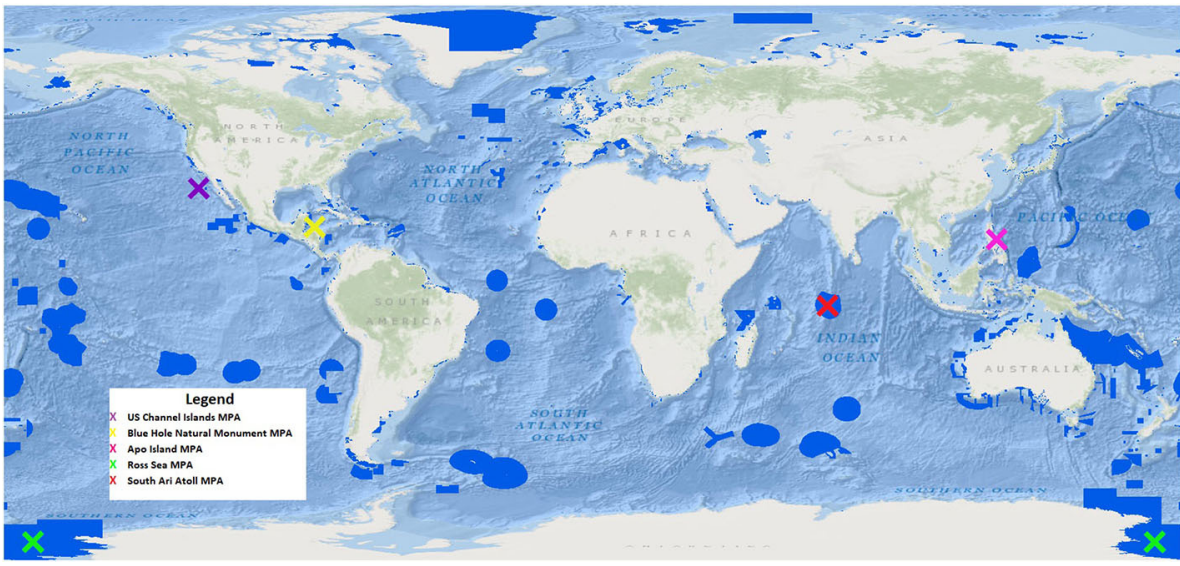

Figure 1

Because the categories of MPAs have such clear goals, the work of creating an MPA is made a bit easier. It is important the process of creating an MPA not be too difficult, because MPAs help to protect the marine environment, from the ocean floor to its surface, and they keep the ocean healthy for our future. The success of MPAs varies, but in general, an MPA is considered successful if its goals and objectives are reached [1]. 


\section{WHAT MAKES A GOOD MARINE PROTECTED AREA?}

Now that we know the goals of MPAs, we can now talk about what conditions make for a good MPA. Scientists have identified five qualities of MPAs that make them really good for protecting the ocean's biodiversity. The best MPAs have the following characteristics:

- No-take zones: As we explained above, a no-take zone means that human activity, such as fishing or boating, is strictly limited to ensure the protection of the marine environment.

- Strong rules: When an MPA has strong rules, it means that if someone does break the rules, there is a way for them to be punished, similar to the way breaking a classroom rule will land you in detention. Enforcement of the rules is difficult in the ocean. First, those enforcing the rules need to be on boats, which can be expensive to own, operate, and upkeep [1]. Second, MPAs, unlike protected areas on land, have many different access points. This means that those looking to break the rules have many ways to get into the MPA [1].

- Old: An "old" MPA means that it has been around for 10 or more years [2]. When an MPA is old, it has been around long enough to make a positive change, such as having more fish of a single type, more types of fish in the area, or bigger fish [2].

- Large size: When it comes to MPAs, bigger is better! A larger MPA means a larger part of the ocean is protected- that also means more ecosystem and species have that protection as well [2].

- Isolated by deep waters and sand: When an MPA is isolated by deep waters or by sand, it is easier to recognize the area as an MPA. Fishers will know that the space is protected, and therefore will know which rules go with that specific MPA [2].

When an MPA has these five features, the MPA generally shows double

\section{BIOMASS}

The total weight or volume of all organisms, in this case, fish.

\section{HIGH SEAS}

Parts of the ocean that are 200 nautical miles (roughly 230 miles) from the shore of a coastal nation. the amount of large fish species and five times more large fish biomass as compared to an unprotected part of the ocean [2]. This means that there are more, and bigger, fish. As of May 2020, just under $7.5 \%$ of the global ocean is protected through MPAs [4]. This may not seem like a lot, but just 20 years ago, $<1 \%$ of the global ocean was protected [4].

\section{WHO CAN MAKE MARINE PROTECTED AREAS?}

So, can anyone create a marine protected area? Well, yes! A local community or a country's government can create MPAs [1]. Individuals who own beaches can create MPAs [1]. These types of MPAs would be closer to shore. But what about far away, in the high seas? $60 \%$ of the ocean falls in what is called the high seas, but $<2 \%$ of the high seas are protected $[3,4]$. Some parts of the high seas are governed by groups that are made up of multiple countries. For example, the 
Figure 2

A map of the Ross Sea MPA. The boxes on the map show where the MPA will be, with the different abbreviations representing different categories of MPAs. The signatures of those who were at the CCAMLR meeting when it was adopted surround the map, including countries and non-governmental organizations (Credit to John B. Weller).

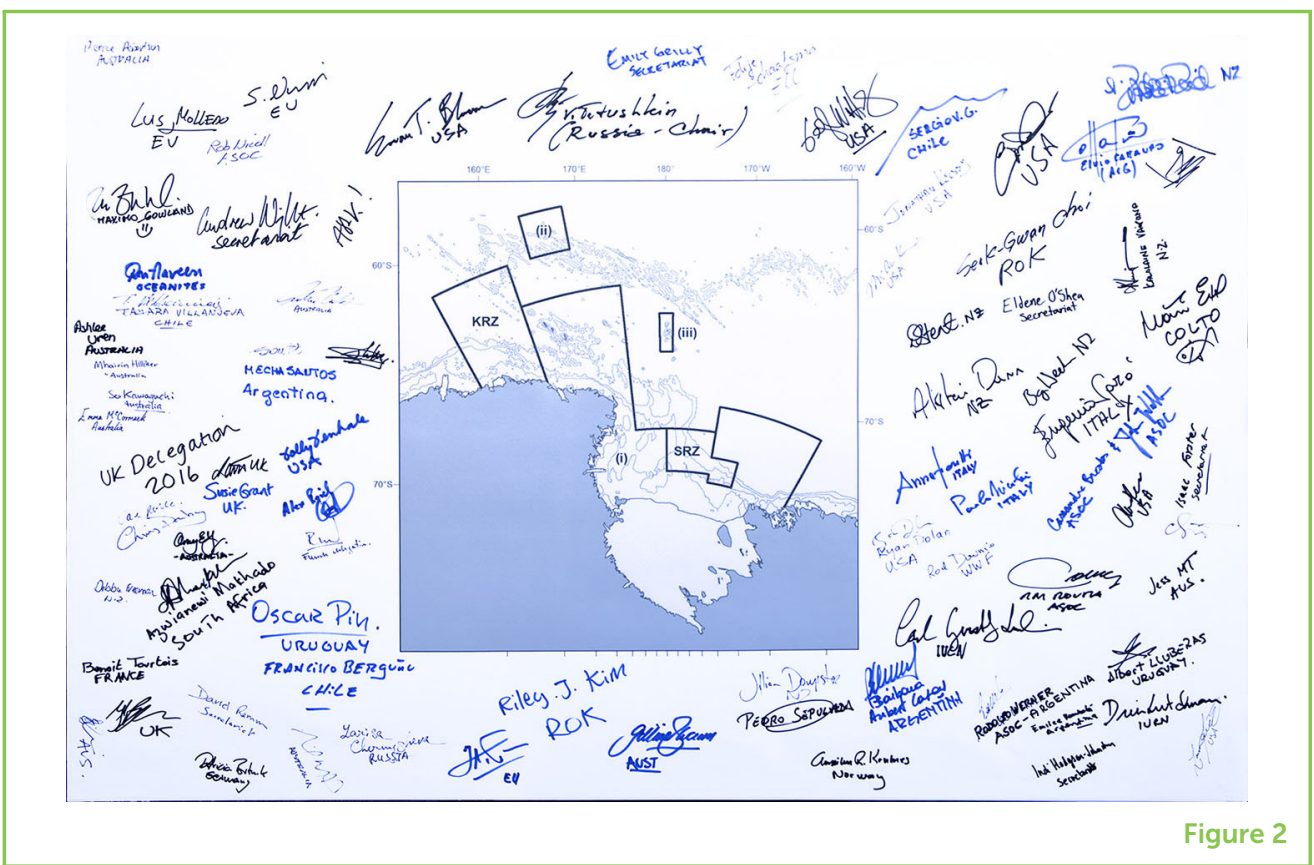

Southern Ocean that surrounds Antarctica is governed by a group called the Commission for the Conservation of Antarctic Marine Living Resources (CCAMLR). This group is composed of 25 countries, along with the European Union. In 2012, two countries submitted an idea for a new MPA in the Southern Ocean [4]. It took until 2016 for the MPA to be allowed, because every country participating had to agree fully (Figure 2) [5]! Called the Ross Sea MPA (Figure 2), it is a category 1A MPA, because its main goal is to conserve the ecosystem and species of the Southern Ocean. It is also currently the largest MPA in the world [4]. What also makes the Ross Sea MPA special is that the Southern Ocean is one of the few really healthy parts of the ocean left, and it is home to important organisms like krill [5].

The Ross Sea MPA is seen as a marine conservation success story, because it is a very large, isolated, no-take MPA that has a lot of support from the countries that came together to create it [3-5]. The Ross Sea MPA is also part of a goal to create a network of MPAs that represent a wide range of marine habitats and environments, especially since so few MPAs exist in the high seas to date [4]. So, not only does the Ross Sea MPA meet four of the five aspects of a good MPA and is unique in its environment, but it also shows that countries can come together and cooperate to conserve parts of the ocean $[3,4]$.

\section{WHY SHOULD WE CARE ABOUT MPAS?}

Marine protected areas are a way for people to come together to preserve our oceans. There are many different types of MPAs, which allows governments or community groups to come together to choose the MPA that is right for their people. For an MPA to be the 
most effective at protecting fish and ecosystems, the MPA should be no-take, have strong rules, be around for a long time, be large in size, and be isolated.

\section{REFERENCES}

1. Day, J., Dudley, N., Hockings, M., Holmes, G., Laffoley, D., Stolton, S., et al. 2012. Guidelines for Applying the IUCN Protected Area Management Categories to Marine Protected Areas. Gland: IUCN.

2. Edgar, G. J., Stuart-Smith, R. D., Willis, T. J., Kininmouth, S., Baker, S. C., Banks, S., et al. 2014. Global conservation outcomes depend on marine protected areas with five key features. Nature 506:216-20. doi: 10.1038/nature13022

3. Gjerde, K. M., Nortdtvedt Reeve, L. L., Harden-Davies, H., Ardron, J., Dolan, R., Durussel, C., et al. 2016. Protecting Earth's last conservation frontier: scientific, management, and legal priorities for MPAs beyond national boundaries. Aquat. Conserv. Mar. Freshw. Ecosyst. 26:45-60. doi: 10.1002/aqc.2646

4. UNEP-WCMC and IUCN. 2020. Marine Protected Planet. Cambridge: UNEP-WCMC; IUCN. Available online at: www . protectedplanet . net

5. Brooks, C. M., Crowder, L. B., Österblom, H., and Strong, A. L. 2019. Reaching consensus for conserving the global commons: the case of the Ross Sea, Antarctica. Conserv. Lett. 13:e12676. doi: 10.1111/conl.12676

SUBMITTED: 27 January 2020; ACCEPTED: 02 November 2020; PUBLISHED ONLINE: 23 November 2020.

EDITED BY: Hervé Claustre, Centre National de la Recherche Scientifique (CNRS), France

CITATION: Nocito ES and Brooks C (2020) Marine Protected Areas: A Way to Protect Our Oceans. Front. Young Minds 8:529996. doi: 10.3389/frym.2020.529996

CONFLICT OF INTEREST: The authors declare that the research was conducted in the absence of any commercial or financial relationships that could be construed as a potential conflict of interest.

COPYRIGHT () 2020 Nocito and Brooks. This is an open-access article distributed under the terms of the Creative Commons Attribution License (CC BY). The use, distribution or reproduction in other forums is permitted, provided the original author(s) and the copyright owner(s) are credited and that the original publication in this journal is cited, in accordance with accepted academic practice. No use, distribution or reproduction is permitted which does not comply with these terms.

\section{YOUNG REVIEWER}

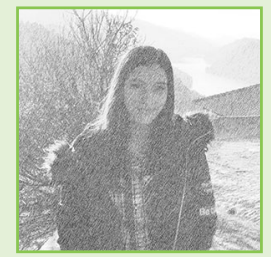

\section{LUANA, AGE: 15}

I like to roller skating, ride a bike, watch movies, and hang out with my friends. 

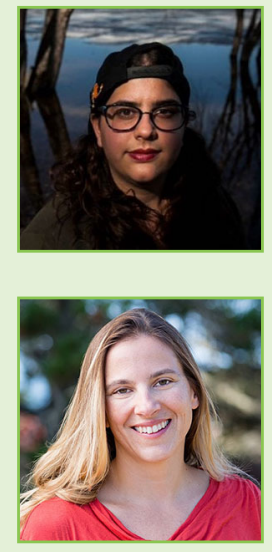

\section{AUTHORS}

\section{EMILY S. NOCITO}

Emily Nocito is currently a Ph.D. student at the University of Colorado-Boulder. She studies marine conservation, with a focus on conserving the high seas. When she is not teaching or in class, she loves to play with her guinea pigs or explore the trails of Colorado. *emily.nocito@colorado.edu

\section{CASSANDRA BROOKS}

Cassandra Brooks is an Assistant Professor in Environmental Studies at the University of Colorado Boulder. She completed her Ph.D. at Stanford University studying international ocean policy, with a focus on marine protection in the Antarctic. During her previous graduate work at Moss Landing Marine Labs, she studied Antarctic toothfish in the Ross Sea, a population that supports the most remote fishery on Earth. Cassandra has worked in the lab, underwater, and at sea-including five research cruises to Antarctica-and has presented and published her work around the world. Cassandra is also trained as a Science Communicator through the University of California Santa Cruz and has published more than 150 articles and multi-media stories about marine science and the environment. Cassandra is also science faculty for the Homeward Bound Project, a ground-breaking women's leadership initiative in Antarctica. 